\title{
The Effect of Zingiber officinale on the Spleen Tissue and Antibody Titer of Broiler Chickens
}

\author{
Alireza Taghdisi ${ }^{1}$ Sajjad Hejazi ${ }^{2}$ \\ ${ }^{1}$ Department of Veterinary Medicine, Tabriz Branch, Islamic Azad \\ University, Tabriz, Iran \\ 2 Department of Anatomy, Tabriz Branch, Islamic Azad University, \\ Tabriz, Iran \\ J Morphol Sci 2019;36:46-50.
}

Address for correspondence Sajjad Hejazi, PhD, Department of Anatomy, Faculty of Veterinary Medicine, Tabriz branch, Islamic Azad University, Tabriz, Iran (e-mail: sajjadhejazi1@gmail.com).

\begin{abstract}
Keywords

- antibody titer

- chicken

- hemagglutination

- spleen

- zingiber officinale
\end{abstract}

Introduction Increasing the immune system's function of fighting infectious diseases is very important in the poultry industry. Ginger, scientifically known as Zingiber officinale, belongs to the Zingiberaceae family. The use of ginger in the diet of poultry increases serum levels of superoxide dismutase enzymes and glutathione peroxidase, which are considered to be important antioxidant enzymes. The main objective of the present study is to evaluate the effect of ginger on the spleen tissue of broiler chickens. Material and Methods The specimens comprised 2 groups of 20 Ross breed broiler chicks, for 42 days and were then, examined and tested. The diet was supplemented with 1 $\mathrm{g} / \mathrm{kg}$ of ginger powder from the beginning of the rearing period. Blood samples of the chicks were randomly collected to measure the levels of hemagglutination (HI). The removed spleens were fixed with $10 \%$ formalin buffer. The specimens were cut in 5 -micron diameters and stained with hematoxylin and eosin.

Results and Conclusion There was a statistically significant difference in the mean of $\mathrm{HI}$ blood titers between the chicks in the growth period and final period groups $(p<0.05)$. The white-pulp tissue samples were more clearly seen in the treatment group than in the control group, and also, it was observed that the wall of the central artery of the white pulp was thicker in the ginger-treated group as compared with the control group. The nutritional value of ginger may vary. Thus, it is necessary to investigate the effect of this plant final on weight gain; the serum factors associated with the metabolic chart, and the response of the immune system to this plant.

\section{Introduction}

Increasing the immune system's function of fighting infectious diseases is very important in the poultry industry. Various factors, such as failure of vaccinations, diseases that suppress the immune system, and unusual use of antibiotics reduce immune responses. Due to high mortality rates in domestic animals and poultry, infectious diseases are a source of concern across the globe. The use of immune stimulants can be one way of improving immunity and reducing the risk of infectious diseases in animals. Ginger, scientifically known as Zingiber officinale, belongs to the Zingiberaceae family. This plant has a variety of species, some of which are edible and often used as medicinal and spice herbs ${ }^{1}$ due to its antioxidant, ${ }^{2}$ antiviral ${ }^{3}$ and antifungal $^{4}$ properties, as well as its enhancing effect on the immune system. ${ }^{5}$ Ginger is used to treat a wide range of diseases. ${ }^{6}$ The use of ginger in the diet of poultry increases serum levels of superoxide dismutase enzymes, catalase, and glutathione peroxidase, which are considered to be important antioxidant enzymes. ${ }^{7}$ Based on research results of Ueki et al ${ }^{8}$ and received

January 20, 2018

accepted

November 20, 2018

published online

February 6, 2019
DOI https://doi.org/

$10.4322 / j m s .088315$. ISSN 2177-0298.
Copyright (e 2019 by Thieme Revinter

Publicações Ltda, Rio de Janeiro, Brazil
License terms

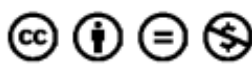


Weidner and sigwart, ${ }^{9}$ the antiinflammatory, antioxidant, antibacterial, antiviral and immunosuppressive properties of this plant make it quite effective in healing headaches, menstrual pains, arthritis, and fever caused by a variety of colds and influenza. As the largest lymph node, the spleen is involved in many activities, including the production of blood cells (lymphocytes), hemoglobin and iron metabolism, red blood cells destruction, blood purification, blood storage, phagocytosis, and immune responses. The most important function in the spleen is the immunological treatment of blood. Therefore, results obtained from this study can be of great value in the economic cycle of the poultry industry, including Jihad agriculture, veterinary offices, universities, chicken coops, and meat products processing. The main objective of the present study is to evaluate the effect of ginger on the spleen tissue of broiler chickens.

\section{Materials and Methods}

In this study, 40 day-old Ross breed broiler chicks were produced in a private sector broiler farm coop in the city of Tabriz. They were completely homogenous in terms of geographical and environmental conditions. The coop was disinfected after being washed with high pressure water. Thereafter, all the chambers, doors, and windows were covered. On the first day, the temperature of the coop was $\sim 32$. It decreased by 1 degree, every 3 days, until it reached 21 at the 27 th breeding season. This temperature remained constant for all groups until the end of the breeding season. In the course of the study, a mixture of natural light during the day and artificial lighting during the night was used to provide the required lighting. All chicks were fed in the same way in terms of diet components and the amount of each component. To provide practical results that can be applied to other studies, the seeds fed to the chicks followed the same current diet. Changes required by the geographical area of breeding parks were implemented according to notification protocol of the country's veterinary administration. The chicks were vaccinated against Newcastle disease, Gambaro, bronchitis, and influenza.

\section{Treatment Implementation Process}

The specimens were considered to be two groups of 20. The diet was supplemented with $1 \mathrm{~g} / \mathrm{kg}$ of ginger powder from the beginning of the rearing period. A total number of 40 dayold Ross breed broiler chicks were grown in a bed system for 42 days, and were examined and tested. Blood samples of chicks were randomly collected on days 10,24 , and 42 to measure the levels of antibody. Blood samples $(100 \mathrm{cc})$ were taken from each chick, and tests of hemagglutination (HI) were referred to a poultry laboratory.

After abdominal autopsy, the weight of spleen specimens was calculated by using digital scales. The spleen was completely removed from the body and fixed with $10 \%$ formalin buffer. Thereafter, histological specimens were sent to the histological laboratory. The specimens were cut in 5-micron diameters and stained with hematoxylin and eosin. Then, they were analyzed under an Eclipse E200-LED microscope (Nikon, Minato, Tokyo, Japan).
Table 1 Comparison of mean values obtained from the antibody titer against Newcastle virus (HI test) between units of control and ginger groups ${ }^{a}$

\begin{tabular}{|l|l|l|}
\hline Parameters & $\begin{array}{l}\text { Normal Group } \\
\boldsymbol{n}=\mathbf{2 0}\end{array}$ & $\begin{array}{l}\text { Treatment Group } \\
\boldsymbol{n}=\mathbf{2 0}\end{array}$ \\
\hline $\begin{array}{l}\text { The initial period } \\
(1-10 \text { days })\end{array}$ & $4.14 \pm 0.253$ & $4.17 \pm 0.282$ \\
\hline $\begin{array}{l}\text { The growth period } \\
(11-24 \text { days })\end{array}$ & $3.44 \pm 0.274$ & $4.36 \pm 0.245^{*}$ \\
\hline $\begin{array}{l}\text { The final period } \\
(24-42 \text { days })\end{array}$ & $3.66 \pm 0.233$ & $4.64 \pm 0.257^{*}$ \\
\hline Spleen weight $(\mathrm{gm})$ & $11.30 \pm 0.3$ & $12.6 \pm 0.4^{*}$ \\
\hline
\end{tabular}

Abbreviation: $\mathrm{HI}$, hemagglutination test.

${ }^{a}$ Values are means \pm standard deviation (SD). ${ }^{*} p<0.05$.

\section{Statistical Analysis of Antibody Titer}

This experiment was conducted with a completely randomized design. The collected data were analyzed using the General Linear Model (GLM) and the Statistical Analysis Software (SAS) (SAS Institute, Cary, NC, USA), and the means were tested using the Duncan multi-domain test (SAS, 2001), with a significance level of $p<0.05 .{ }^{10}$

\section{Results}

\section{Results of HI Tests Variance Analyses}

The Initial Period (1-10 Days)

As shown in - Table 1, according to the results of this study, there was no statistically significant difference in the mean of $\mathrm{HI}$ blood titers between the normal and treatment groups at the beginning of the study $(p>0.05 ; 4.14 \pm 0.253,4.17 \pm 0.282)$.

\section{The Growth Period (11-24 Days)}

The results in - Table $\mathbf{1}$ show a statistically significant difference in the mean of $\mathrm{HI}$ blood titers between the normal and treatment groups during the growth period $(p<0.05$; $3.44 \pm 0.24,4.36 \pm 0.245$ ).

\section{The Final Period (24-42 Days)}

The results in -Table 1 show a statistically significant difference in the mean of $\mathrm{HI}$ blood titers between the normal and treatment groups during the final period $(p<0.05$; $3.66 \pm 0.223,4.64 \pm 0.257$ ).

The Result of Mean Spleen Weight in Broiler Chicks at the End of the Period

The results in -Table 1 show a statistically significant difference in the mean of spleen weight between the normal and treatment groups at the end of the period $(p<0.05$; $11.3 \pm 0.03,6.12 \pm 0.40)$.

\section{Result of Microscopy}

The analysis of the spleen specimen showed that the spleen was surrounded by a hard connective capsule that had penetrated into the tissue through subtle branches. The 
spleen tissue is formed from two red and white connectors. The white pulp contains the structure of the lymph nodes and central arteries, which was clearly evident in samples prepared in the ginger-treated group, at 42 days; areas covered by this pulp are generally unclear in birds and uncommon in mammals. In this study, white pulp tissue samples were more clearly seen in the treatment group than in the control group at the end of the period ( - Fig. 1A-B).

Collagen conjugation and fibrocystic connective cells were observed while analyzing the spleen tissues. However, smooth muscle cells in the mammalian capsule were not seen in any of the two groups. It was observed that the central artery of the white pulp was thicker in the gingertreated group as compared with the control group ( - Fig. 1CD). Differently from mammals, in which this area is clearly identifiable, the marginal area of the border between the white pulp and the red pulp was not observed in any of the groups. Although the compression and density of lymphocytic cells of the white pulp turned out to be higher in the treatment group, the number of these cells was higher in the control group. High compression and density of lymphocyte cells in the treatment group caused the white pulp border to be more recognizable in compare to normal group ( - Fig. 1E-F). No smooth-cell membranes were observed in the analyzed spleen tissues of participating groups, and the trabecular penetration into the parenchyma tissue was rarely seen, which led to blood vessels passing into the spleen parenchyma tissue. The range of the red pulp in the studied samples turned out to be more limited than in mammals. The compression and density of red pulp cells turned out to be higher among the treatment group, and the nuclei of the RBC cells were clearly visible.
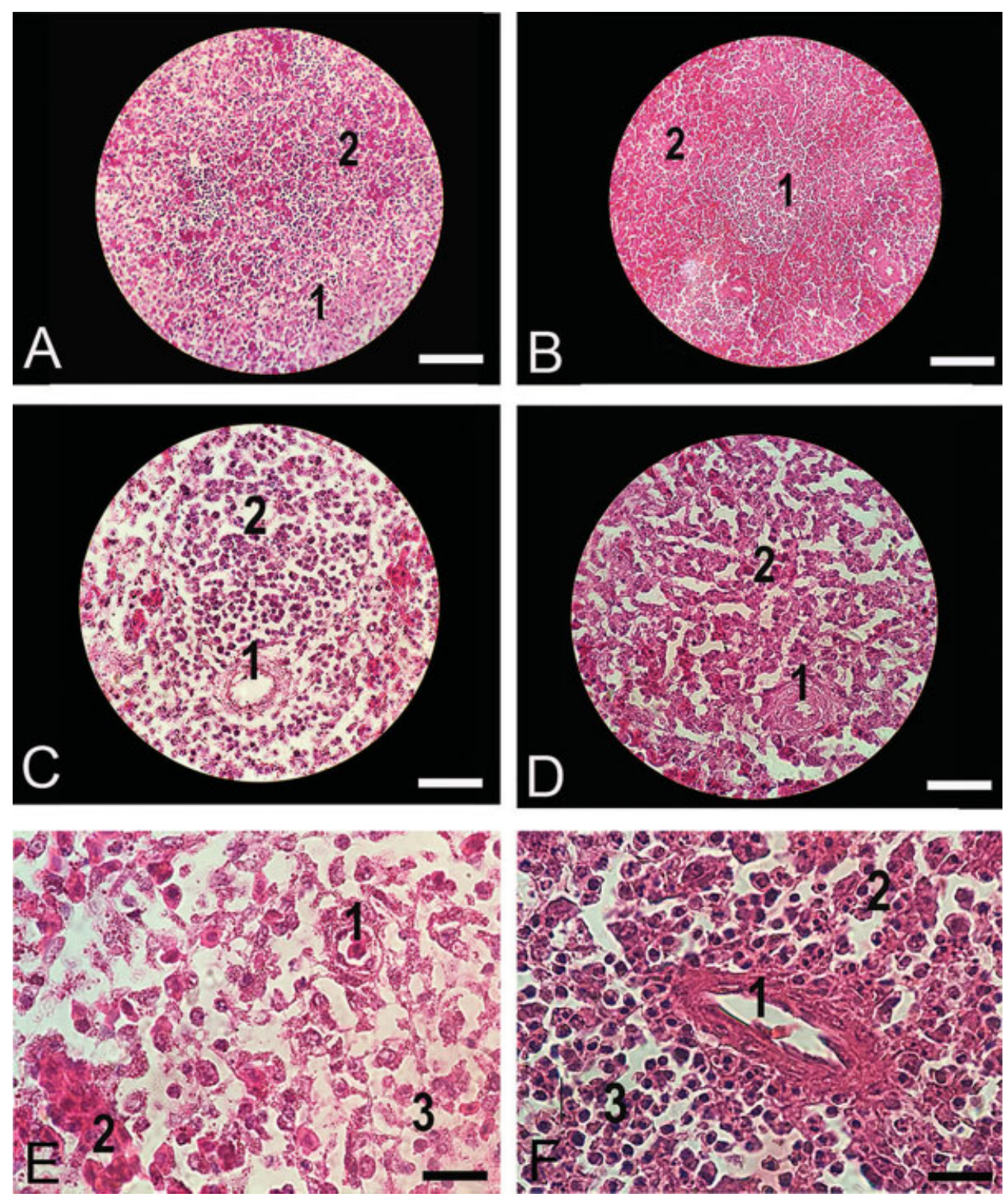

Fig. 1 Microscopic view of the spleen tissue of a broiler chicken. (A) Normal group (B) Treatment group. 1 - white pulp 2 - red pulp (hematoxylin \& eosin [H\&E] sainting, scale bar $=30 \mu \mathrm{m})$. (C) Normal group (D) Treatment group. 1 - central artery 2 - white pulp (H\&E sainting, scale bar $=20 \mu \mathrm{m})$. (E) Normal group (F) Treatment group. 1 - central artery 2 - red pulp 3 - white pulp (H\&E sainting, scale bar $=10 \mu \mathrm{m}$ ). 


\section{Discussion and Conclusion}

Ginger reduces lipid peroxidation and increases antioxidant capacity of the plasma. ${ }^{11}$ The use of ginger in the diet of poultry increases serum activity of superoxide dismutase enzymes, catalase, and glutathione peroxidase, which are considered to be important antioxidant enzymes. ${ }^{7}$ In their histology book, Bloom and Fawcett ${ }^{12}$ state that the spleen has been characterized by the accumulation of white pulp in tissues of central arteries and red pulp fills the spaces between the vascular sinus. The distribution and relative value of white and red pulp in different species of animals differ significantly so that during their immune responses or in adverse conditions, the formation and destruction of blood cells are altered. Animal species that have high blood volume (like horse, cattle, and dog) have low white pulp, solid structure, and smooth muscle connective tissue capsules. On the other hand, species that have low blood volume (like rabbits, rodents, and birds) have high white pulp, subtle structure, and poorly developed flat material. Based on the results of this study and consistent with Bloom and Fawcett, ${ }^{12}$ a predominant white pulp to red pulp ratio was found in the spleen tissue of broiler chickens. The outer surface of the spleen is surrounded by a hard connective capsule, and the cylindrical trabeculae extend to the spleen parenchyma. Their cellular elements are fibroblasts. In rabbits, rodents, and birds, smooth muscle cells in the capsule and trabecula are rarely seen, and any changes in spleen volume are attributed to changes in blood flow to this organ. Smooth muscles are much more frequent in the capsules and trabeculae of equine, ruminant and carnivores, and regular contraction of the spleen is smooth due to contraction of muscle cells. ${ }^{12}$ Hodges ${ }^{13}$ also pointed out that the spleen tissue of poultry contains unclear red and white pulp, and differently from mammals, there is no trabeculae split. The results of a study conducted by Pourhaji and Abbaszadeh ${ }^{14}$ indicated the presence of unclear pulps and the absence of splits in the spleen tissue of birds. However, Nasu et $a{ }^{15}$ reported delicate connective trabeculae in the spleen tissue of pigeons. During observations conducted in this study, no trabecular structure or smooth muscle cells in the parenchyma of the spleen tissue were found. Additionally, areas covered with red and white pulp tuned out to be more identifiable in the treatment group as compared with the control group. In this study, it was observed that the central pulmonary artery of the white pulp was thicker in the ginger-treated group as compared with the control group, indicating the effectiveness of ginger in increasing blood flow to the tissue. The lymphocytic cells of the white pulp in the treatment group showed high compression and density as compared with the control group; whereas in the control group, there was a larger space between lymphocyte cells, showing a difference in the density of lymphocytic cells in the treatment and control groups. The analysis results of the immune response of broiler chicks showed that ginger can have an immune booster effect in a short period of time. Hence, there is a statistically significant difference between the control and treatment groups from the time of growth to the end of the final period. Results obtained from analyzing the weight of the spleen (considered to be the main indicator in the immune system) signified the fact that supplementing the diet of chicks with ginger caused weight gain at the end of the study. As reported by Katanbaf et al, ${ }^{16}$ the relative weight gain of lymphoid organs is a sign of progression of the immune system. Al Khalifa et a ${ }^{17}$ have shown that increasing the use of fish oil (as antioxidant) in the diet increases the weight of the spleen. Wang et al ${ }^{18}$ have shown that diets of laying hens contain omega-3 fatty acids (as antioxidants), which improve the growth of lymphatic organs (like the spleen) within four weeks of feeding. In this study, consistent with the results of Wang's study, ginger functioned as an antioxidant, and increased the relative weight of the spleen and the hemorrhagic immune system. Considering that ginger contains the same antioxidants, it can be claimed that it protects fatty acids of the humoral immune system; hence, it can be noted that antioxidant agents like ginger prevent the formation of free radicals due to the oxidation of fatty acids, causing final improvement in the function of the humoral system. It can be concluded that ginger could have antiviral properties against the Newcastle virus by enhancing the efficiency of the immune system. According to the findings of this study, ginger powder could have a positive effect on growth performance and immune system in broiler chicks due to the presence of antibacterial properties of ginger oil and other compounds. Based on studies by Ueki et $\mathrm{al}^{8}$ and Weidner and Sigwart ${ }^{9}$ conducted to determine the effect of ginger on healing sore throat, arthritis, and fever caused by a variety of colds and influenza, it can be said that the antiinflammatory, antioxidant, antibacterial, and antiviral properties of ginger can function as an immune system booster through enhancing blood supply and strengthening the immune function of the body. The results of this study showed that using $1 \%$ ginger in the diet can improve immune functions and the immune system.

Promotion of growth indices in the poultry farming industry is of particular importance and different studies are being performed on nutritional and management principles to produce of the highest quality. Since ginger may have different nutritional values, it is necessary to investigate the effect of this plant on final weight gain, the serum factors associated with the metabolic chart, and the response of the immune system to this plant. Therefore, it is highly recommended that further research is conducted on the promotion of poultry immunity against Newcastle disease using different amounts of ginger in the broiler chicken diet.

\section{Conflicts of Interest}

The authors have no conflicts of interest to declare.

\section{References}

1 Kapoor LD. Handbook of Ayurvedic Medicinal Plants: Herbal Reference Library. CRC Press; 2000:424

2 Grzanna R, Lindmark L, Frondoza CG. Ginger-an herbal medicinal product with broad anti-inflammatory actions. J Med Food 2005; 8(02):125-132 
3 Denyer CV, Jackson P, Loakes DM, Ellis MR, Young DAB. Isolation of antirhinoviral sesquiterpenes from ginger (Zingiber officinale). J Nat Prod 1994;57(05):658-662

4 Agarwal M, Walia S, Dhingra S, Khambay BP. Insect growth inhibition, antifeedant and antifungal activity of compounds isolated/ derived from Zingiber officinale Roscoe (ginger) rhizomes. Pest Manag Sci 2001;57(03):289-300

5 Nya EJ, Austin B. Use of dietary ginger, Zingiber officinale Roscoe, as an immunostimulant to control Aeromonas hydrophila infections in rainbow trout, Oncorhynchus mykiss (Walbaum). J Fish Dis 2009;32(11):971-977

6 Ernst E, Pittler MH. Efficacy of ginger for nausea and vomiting: a systematic review of randomized clinical trials. $\mathrm{Br} J$ Anaesth 2000; 84(03):367-371

7 Khan RU, Naz S, Nikousefat Z, et al. Potential applications of ginger (Zingiberofficinale) in poultry diets. Worlds Poult Sci J 2012;68 (02):245-252

8 Ueki S, Miyoshi M, Shido O, Hasegawa J, Watanabe T. Systemic administration of [6]-gingerol, a pungent constituent of ginger, induces hypothermia in rats via an inhibitory effect on metabolic rate. Eur J Pharmacol 2008;584(01):87-92

9 Weidner MS, Sigwart K. The safety of a ginger extract in the rat. J Ethnopharmacol 2000;73(03):513-520
10 SAS Institute. SAS/STAT User's Guide. Release 8.02 ed. Cary, NC: SAS Institute Inc.; 2001

11 Arkan BM, Al-Rubaee MAM, Jalila Q. Effect of Ginger (Zingiber officinale) on Performance and Blood Serum Parameters of Broiler. Int J Poult Sci 2012;11(02):143-146

12 Bloom and Fawcett. A textbook of histology. 1st ed. CRC Press; 1998

13 Hodges RD. The histology of the fowl. 1st ed. London: Academic Press, London, New York: San Francisco, 1974:88-101

14 Pourhaji J, Abbaszadeh P. Morphological and histological study of the liver, spleen and pancreas in Guinea fowl. Pajouhesh \& Sazandegi 2015;28(106):76-83

15 Nasu T, Shimizu K, Nakai M. Morphological study of the dove spleen. Poult Sci 1992;71(09):1527-1530

16 Katanbaf MN, Dunnington EA, Siegel PB. Restricted feeding in early and late-feathering chickens. 1 . Growth and physiological responses. Poult Sci 1989;68(03):344-351

17 Al-Khalifa H, Givens DI, Rymer C, Yaqoob P. Effect of n-3 fatty acids on immune function in broiler chickens. Poult Sci 2012;91(01): $74-88$

18 Wang SY, Lin HS. Antioxidant activity in fruits and leaves of blackberry, raspberry, and strawberry varies with cultivar and developmental stage. J Agric Food Chem 2000;48(02):140-146 